\title{
Prevalence and correlates of intimate partner violence among older Chinese couples in Hong Kong
}

\author{
Elsie Yan and Ko Ling Chan \\ Department of Social Work and Social Administration, The University of Hong Kong, Hong Kong
}

ABSTRACT

Background: This study examined the prevalence and risk factors for intimate partner violence (IPV) among Chinese older couples in Hong Kong.

Methods: A population representative sample was surveyed.

Results: The prevalence of IPV in older adults was found to be quite high in the present study, with a lifetime prevalence ranging from $1.4 \%$ to $53.6 \%$, and a past year prevalence ranging from $0.4 \%$ to $36.1 \%$ for various forms of aggression. Results of logistic regression analyses showed that older persons who were younger among this "older" group, who were not employed, who had a substance abuse problem, who had witnessed parental violence during their childhood, who had a criminal history, who had a low level of assertiveness, who had an anger management problem, who experienced a low level of social support and/or experienced stressful conditions, were all more likely to fall victims of IPV.

Conclusion: It is suggested that IPV in older couples is a complex phenomenon that is closely intertwined with other forms of domestic violence, including spousal violence, child abuse, in-law conflicts, and elderly adult abuse. Thus, before we have more definitive and concrete evidence that IPV in older couples should definitively come under the category of elder abuse or IPV, it is advisable to treat it under its own separate category of family violence.

Key words: violence/aggression, elder abuse

\section{Introduction}

Older persons undergoing intimate partner violence (IPV) form a shadowy group falling between the categories of wife abuse and elder abuse (Straka and Montminy, 2006). In wife abuse, older victims are thought to comprise a minority. In elder abuse, violence within the context of intimate relationships is seldom recognized. Furthermore, although men also fall victim to IPV, this is typically overlooked (Dutton and Nicholls, 2005). The present study is an attempt to address this existing research gap and to establish the prevalence and risk factors for IPV in older Chinese men and women in Hong Kong.

\section{IPV in younger and older adults}

In contrast to the general perception that IPV diminishes as relationship partners grow old, Wilke

Correspondence should be addressed to: Dr. Elsie Yan, Department of Social Work and Social Administration, The University of Hong Kong, Pokfulam, Hong Kong. Phone: +852-2219 4373; Fax: +852-2858 7604. Email: elsieyan@hkucc.hku.hk. Received 16 Sep 2011; revision requested 1 Nov 2011; revised version received 30 Jan 2012; accepted 7 Feb 2012. First published online 27 March 2012 and Vinton (2005) found that older women experience more IPV than younger women. Specifically, $41 \%$ of the women aged 45 years and older versus $36 \%$ of those aged $30-44$ and $26 \%$ of those aged 18-29 reported being in a violent relationship. The duration of abuse was also found to be much longer for older women, lasting an average of $14.5,5.5$, and 2.6 years in three separate cohorts of women, respectively. This indicates that there is not a falling-off in abuse because of the frailty and dependence which come with aging, and it is speculated that older women who have survived IPV may have been involved in a long-standing violent relationship.

\section{Risk factors for IPV in older adults}

Drawing upon the National Violence against Women Survey, Jasinski and Dietz (2003) examined the physical violence perpetrated by partners reportedly experienced by respondents over 55 years of age. They found that women were three times more likely to report the experience of physical assault by their current partner than men, with individuals who were married, whose partner 
was in poorer health, and/or who reported that their partner drank alcohol having greater odds of being a victim of IPV.

Given the limited empirical evidence regarding the risk factors specific for IPV in older adults, it is helpful to review the literature on elder abuse and IPV in general. The existing literature suggests that various situational and demographic variables are related to the occurrence of elder abuse. In terms of the situational variables, both social isolation and a shared living environment are major factors related to elder abuse (Shugarman et al., 2003). The empirically based demographic characteristics of older adults are mixed in terms of the impact of gender. Some studies have actually reported that there are more males than females who are abused (Pillemer and Finkelhor, 1988), whereas others suggest that the majority of victims are female (Barnett et al., 1997). In either case, older adults with cognitive or physical impairments are more likely to be abused by their caregivers (Choi and Mayer, 2000).

For risk factors specific to IPV, it has been found that abusive partners tend to be unemployed or of a low socioeconomic status (Parish et al., 2004; $\mathrm{Xu}$ et al., 2005), abuse alcohol and drugs (Parish et al., 2004; Xu et al., 2005), and have poor anger management (Chan, 2004) or suffer sexual jealousy (Parish et al., 2004). Male domination has also been identified as an important risk factor for violence against women (Xu et al., 2005) and so has conflict with the perpetrator's mother-in-law (Chan et al., 2008).

The aim of the present study was to study the prevalence and risk factors for IPV in older Chinese couples in Hong Kong using a representative population sample.

\section{Methods}

This study was approved by the ethics committee of the University of Hong Kong.

\section{Study design and sample}

The data employed in this analysis were a subsample from a representative population study on IPV using a household survey which was carried out in 2004. A complete description of the research design and sampling is available (Chan et al., 2008). Cantonese, Putonghua, or English speaking individuals aged 16 years or above at the time of the study, who were either married or cohabiting, or were single or divorced but with children, were eligible to participate. All subjects participated voluntarily without monetary reward. After explanation of the study and confidentiality issues, written informed consent was obtained from all of the participants. They were then individually interviewed face-to-face by trained research assistants. With a response rate of $71 \%$, this survey was a representative sample of 5,049 adult respondents.

The data employed in this analysis included only those participants who were aged 60 years or above and who were married or cohabiting at the time of the interview. A total of 937 cases (397 women and 540 men) were extracted and included in this analysis.

\section{Measures}

\section{DEPENDENT VARIABLES}

Intimate partner violence. The Revised Conflict Tactics Scale (CTS2) was employed to measure partner violence in terms of lifetime and precedingyear prevalence. The CTS2 covers five aspects of spousal conflicts - negotiation, physical assault, psychological aggression, physical injury, and sexual coercion. It has been demonstrated to have satisfactory psychometric characteristics (Straus, 1990) and high cross-cultural reliability (Straus, 2004). The internal consistency reliability of the CTS2 scales is generally high, with an $\alpha$ coefficient ranging from 0.79 to 0.95 (Straus et al., 1996). The CTS2 has been translated into Chinese and validated using Hong Kong data (Chan, 2004). In this study, the observed $\alpha$ reliability ranged from 0.88 to 0.96 .

\section{INDEPENDENT VARIABLES}

Demographic characteristics. Participants provided information on their age, gender, education level, marital status, disability and chronic illness, living arrangements, work status and income, whether they were receiving social security, whether they were in debt, and whether they were new immigrants to Hong Kong.

Childhood witness of parental violence. Participants were asked to recall if they had witnessed parental use of physical violence and injury in childhood, as described by the physical assault and injury scales of the CTS2.

In-law conflicts. In-law conflict was measured by a single item. Participants were asked to report the number of incidents of conflict with children-in-law in the previous 12 months. The responses included never, once, twice, 3-5 times, 6-10 times, 11-20 times, 20 times or more, and none in the past 12 months but it has happened before.

Risk factors for intimate partner violence. Risk factors for IPV were measured using the Family Needs Screener (FNS; Kantor and Straus, 1999). The 
FNS is a short version of the Personal and Relationships Profile (PRP) which is a multiscale instrument that profiles various empirically demonstrated variables related to physical violence against a spouse in a marital, cohabiting, or dating relationship, with reportedly satisfactory internal reliability (Straus and Mouradian, 1999). The PRP items are arranged in 21 subscales which are theoretically related to the etiology of IPV and measure both individual and relationship factors. For the present study, six subscales were selected from the PRP to estimate their correlation with partner violence. These were criminal history, domination, jealousy, anger management, substance abuse (including alcohol and/or drug abuse), and stressful conditions. Respondents were asked to indicate the extent to which each statement adequately described themselves on a 4-point scale, with a higher score indicating a higher risk for IPV.

Social support. Social support was measured by the social support scale from the FNS (Kantor et al., 1999). The items of the social support scale include the following items: only have a few friends/family to help with a child/children; feel very isolated; there is someone who makes me feel confident; there is someone with whom I can talk openly; there is someone with whom I can talk about my relationship problems; there is someone from whom I can borrow money in an emergency; I have someone to take care of my children in an emergency; someone who helps me around the house; I have someone I can count on in times of need; there is enough money for my daily needs.

For the present study, the PRP subscales and the social support scale were translated into Chinese by the second author. A back translation was conducted to ensure compatibility with the original scale. The Chinese version was further checked by two clinical psychologists and three experienced social workers with experience working with family violence. The reliability $\alpha$ of the anger management subscale was 0.52 . The reliability $\alpha$ of the subscales including domination, jealousy, anger management, substance abuse, and stressful conditions ranged from 0.78 to 0.97 . The $\alpha$ coefficient of the social support scale was 0.71 .

\section{Results}

\section{Participants}

The participants' age ranged from 60 to 100 years with a mean of 68.6. Approximately $15.5 \%$ had attended high school (equivalent to grade 10 or above in the USA) or tertiary education.
Approximately $3.5 \%$ identified themselves as physically or mentally challenged. Nearly half of the participants reported a chronic illness that required medical treatment, a condition slightly more common in females $(49.5 \%)$ than in males $(40.9 \%)$. Approximately $64 \%$ of the subjects were living with their children and $38.6 \%$ were new immigrants from Mainland China. Seventy-eight percent had no income and approximately $13.2 \%$ were dependent on social security. More men than women were dependent on social security $\left(\chi^{2}=\right.$ $5.122, \mathrm{p}<0.05)$ or were still employed $\left(\chi^{2}=\right.$ $36.210, p<0.001)$ at the time of the interview

The demographic characteristics of the present sample are summarized in Table 1.

\section{Prevalence}

The lifetime prevalence of various forms of aggression ranged from $1.4 \%$ to $53.6 \%$ in this sample. Psychological aggression and sexual abuse, respectively, were the most and the least prevalent forms of abuse reported in this sample. No significant gender difference was observed in terms of the lifetime prevalence of the various forms of IPV.

The past-year prevalence of IPV ranged from $0.4 \%$ to $36.1 \%$. Psychological aggression was the most common form of IPV reported by respondents in this sample, with $36.1 \%$ of the respondents reporting their partners had used some form of psychological aggression on them in the surveyed year. Physical assault and sexual abuse were reported by $2.5 \%$ and $1.2 \%$ of the respondents, respectively. With the exception of total physical assault $\left(\chi^{2}=4.096, p<0.05\right)$, and total physical or sexual injury $\left(\chi^{2}=5.615, p<0.05\right)$, both of which were more common in males than in females, no significant gender difference was observed in terms of the lifetime prevalence of the various forms of IPV.

Lifetime and past-year prevalence rates of the forms of IPV broken down by gender are summarized in Table 2.

\section{Risk factors for IPV}

A series of binary logistic regression analyses were conducted to unearth associations between IPV and the participants' demographic, psychosocial, and relationship characteristics.

The demographic variables of interest included gender, age, education level, disability, chronic illness, coresidence with adult child(ren), whether the participant was a new immigrant, employment status, social security, indebtedness, and income. An examination of the adjusted odds ratio showed that different demographic characteristics were 
Table 1. Demographic characteristics of the respondents

\begin{tabular}{|c|c|c|c|c|c|c|c|}
\hline \multirow[b]{2}{*}{ CHARACTERISTICS } & \multicolumn{2}{|c|}{$\begin{array}{c}\text { ALL } \\
(n=937)\end{array}$} & \multicolumn{2}{|c|}{$\begin{array}{c}\text { MALE } \\
(n=540)\end{array}$} & \multicolumn{2}{|c|}{$\begin{array}{l}\text { FEMALE } \\
(n=397)\end{array}$} & \multirow[b]{2}{*}{$\chi^{2} / t-\operatorname{TEST}$} \\
\hline & $n$ & $\%$ & $n$ & $\%$ & $n$ & $\%$ & \\
\hline Age (mean, SD) & 68.60 & 6.62 & 68.84 & 6.72 & 68.26 & 6.46 & 1.324 \\
\hline Education & & & & & & & 2.159 \\
\hline Form 3 or below & 792 & 84.5 & 451 & 83.5 & 341 & 85.9 & \\
\hline Form 4-7 & 85 & 9.1 & 49 & 9.1 & 36 & 9.1 & \\
\hline Tertiary or above & 60 & 6.4 & 40 & 7.4 & 20 & 5.0 & \\
\hline Marital Status & & & & & & & - \\
\hline Married/Cohabited & 937 & 100 & 540 & 100 & 397 & 100 & \\
\hline Disability & 33 & 3.5 & 24 & 4.4 & 9 & 2.3 & 3.193 \\
\hline Chronic illness & 416 & 44.5 & 220 & 40.9 & 196 & 49.5 & $6.834^{* *}$ \\
\hline Coresidence with children & 592 & 63.2 & 359 & 66.5 & 233 & 58.7 & $5.970^{*}$ \\
\hline New immigrants & 362 & 38.6 & 201 & 37.2 & 161 & 40.6 & 1.071 \\
\hline Employed & 109 & 11.6 & 92 & 17.0 & 17 & 4.3 & $36.210^{* * *}$ \\
\hline Income group & & & & & & & $19.787^{*}$ \\
\hline No income & 729 & 78.0 & 397 & 73.7 & 332 & 83.8 & \\
\hline HK $\$ 4,999$ or below & 104 & 11.1 & 63 & 11.7 & 41 & 10.4 & \\
\hline HK $\$ 5,000$ or above & 102 & 10.9 & 79 & 14.7 & 23 & 5.8 & \\
\hline Receiving social security & 116 & 13.2 & 78 & 15.4 & 38 & 10.2 & $5.122^{*}$ \\
\hline Indebtedness & 23 & 2.6 & 17 & 3.3 & 6 & 1.6 & 2.533 \\
\hline
\end{tabular}

${ }^{*} \mathrm{p}<0.05 ;{ }^{* *} \mathrm{p}<0.01 ;^{* * *} \mathrm{p}<0.001$.

Table 2. Lifetime and preceding-year prevalence of IPV victimization and in-law conflict

\begin{tabular}{lrrrr}
\hline & TOTAL $\%$ & MALE $\%$ & FEMALE $\%$ & $\chi^{2}$ \\
Lifetime prevalence & & & & \\
Physical assault - Total & 6.6 & 6.8 & 6.2 & 0.142 \\
Physical assault - Severe & 2.6 & 2.1 & 3.4 & 1.416 \\
Sexual abuse - Total & 3.2 & 3.1 & 3.5 & 0.108 \\
Sexual abuse - Severe & 1.4 & 1.5 & 1.3 & 0.063 \\
Psychological aggression - Total & 53.6 & 55.8 & 50.6 & 2.415 \\
Psychological aggression - Severe & 36.7 & 37.7 & 35.5 & 0.461 \\
Physical or sexual or injury - Total & 7.7 & 8.0 & 7.2 & 0.234 \\
Physical or sexual or injury - Severe & 3.2 & 3.0 & 3.6 & 0.239 \\
Preceding-year prevalence & & & & \\
Physical assault - Total & 2.5 & 3.4 & 1.3 & $4.096^{*}$ \\
Physical assault - Severe & 0.7 & 1.0 & 0.3 & 1.629 \\
Sexual abuse - Total & 1.2 & 1.5 & 0.8 & 0.975 \\
Sexual abuse - Severe & 0.4 & 0.6 & 0.3 & 0.470 \\
Psychological aggression - Total & 36.1 & 37.9 & 33.7 & 1.692 \\
Psychological aggression - Severe & 24.0 & 23.9 & 24.2 & 0.009 \\
Physical or sexual or injury - Total & 2.9 & 4.0 & 1.3 & $5.615^{*}$ \\
Physical or sexual or injury - Severe & 1.0 & 1.5 & 0.3 & 3.629 \\
\hline
\end{tabular}

${ }^{*} \mathrm{p}<0.05$.

independently associated with various forms of IPV. The perpetration of physical abuse was associated with a younger age of the victim $(\mathrm{OR}=0.848$, $\mathrm{p}<0.001)$, not being employed ( $\mathrm{OR}=0.105$, $\mathrm{p}<0.05)$, and having an income $(\mathrm{OR}=0.189$, $\mathrm{p}<0.05)$; psychological abuse was associated with a younger age of the victim $(\mathrm{OR}=0.970, \mathrm{p}<0.05)$; sexual abuse was associated with having an income $(\mathrm{OR}=0.129, \mathrm{p}<0.05)$.

The psychosocial and relationship variables of interest included conflict with children-in-law, substance abuse, witnessing parental violence in childhood, criminal history, domination, jealousy, anger management, social support, and stressful 
conditions. The results showed that while substance abuse increased the risk for physical and sexual abuse 20- and 35-fold, respectively (OR $=20.763$ and 35.330, $\mathrm{p}<0.001)$, criminal history also increased the risk for physical and sexual abuse by 18 and 21 times, respectively $(\mathrm{OR}=18.281$ and $21.108, \mathrm{p}<0.001)$. A low level of social support also increased the odds of physical abuse (OR = $0.149, \mathrm{p}<0.05)$. A low level of anger management and a high number of stressful conditions were both independently associated with higher levels of psychological aggression $(\mathrm{OR}=0.393$ and 1.397, $\mathrm{p}<0.01$ and 0.05 ).

Tables 3 and 4 present the results of the logistic regression analyses.

\section{Discussion}

The present study used a representative sample to determine the prevalence of IPV in older Chinese couples in Hong Kong. In doing so, our team sought to identify the significantly related demographic, psychosocial, and relational risk factors.

Previous local studies on IPV in the comparatively younger population using representative samples have typically reported a past-year prevalence of $16 \%-26 \%$ (Leung et al., 1999; Xu et al., 2005). Compared to these reported rates, the prevalence of IPV in older adults was found to be quite high in the present study, with a lifetime prevalence ranging from $1.4 \%$ to $53.6 \%$ and a pastyear prevalence ranging from $0.4 \%$ to $36.1 \%$ for various forms of aggression.

It is unclear whether IPV in older adults bears a closer resemblance to IPV or elder abuse. On one hand, it is possible that these IPV cases in older adults are a form of spousal abuse in a couple that is growing old, meaning that the IPV victims in the present study may have been survivors of a long-standing violent relationship. On the other hand, it is also possible that these cases are better understood as elder abuse, wherein a person falls victim to abuse because of his or her frailty and decreased capacity for self-care due to advanced age. While it is too early to draw a conclusion, an investigation into the factors associated with IPV in older couples may begin to throw some urgently needed light on this special group.

Our study found that older men, not women, were more likely to become victims of physical abuse by an intimate partner in the surveyed year. This finding contrasts with previous research which showed physical abuse more commonly occurring in women. A previous incidence study showed that two-thirds of the victims of physical abuse were older females (National Center on Elder Abuse,
1998). Another study examining older victims in the domestic violence service system also showed an overwhelming majority of the victims $(90.1 \%)$ to be female (Lundy and Grossman, 2004). While both studies used data from adult protective services, referrals, and service systems, the results may not be closely comparable to the present findings due to various methodological or sampling differences. In fact, however, a previous study using random samples also found that more males than females were abused (Pillemer and Finkelhor, 1988). It is possible that while older persons of both genders are victims of IPV, older females may be more inclined to seek help from service agencies or were in some similar sense more easily identified, and have thus been better represented in certain previous studies.

An examination of the demographic correlates of IPV among older couples showed that while it resembles both elder abuse and IPV in younger couples, there is also a considerable difference between them: For instance, this study found that among the older victims of IPV, those who were relatively younger among them were at elevated risk for IPV. This finding contradicts the general perception that advanced age per se is associated with increased risk of elder abuse. However, this is less of a surprise when taking into account the fact that only a fraction of elderly adult abuse cases are actually reported. The results from the national elderly adult abuse incidence study showed that the oldest old are overrepresented among the cases reported to adult protective services but nevertheless still underrepresented in that they make up the highest number of non-reported cases. Specifically, among the elder abuse cases reported to adult protective services, approximately half of the victims were 80 years of age or above. The opposite is observed in non-reported cases, however, with 60-70-year olds comprising almost $70 \%$ of the cases of physical abuse (National Center on Elder Abuse, 1998). It is also noteworthy that much of the elder abuse literature focuses on victims' adult children as the abusers (National Center on Elder Abuse, 1998). It is possible that a victim's age may have different implications for IPV in older couples.

Previous reports on the association between substance abuse, criminal history, and domestic violence have largely focused on the perpetrators. In the elder abuse literature, abusers are reported to engage in both drinking and getting drunk (Anetzberger et al., 1994), and most had consumed alcohol before perpetrating acts of violence (Eckley and Vilakazi, 1995). In the field of IPV research, abusive partners tend to use or abuse alcohol and drugs (Parish et al., 2004; Xu et al., 2005). Findings from the present study showed that older 
Table 3. Demographic correlates associated with preceding-year IPV victimization as shown by regression analyses

\begin{tabular}{|c|c|c|c|c|c|c|c|}
\hline \multirow[b]{2}{*}{ CHARACTERISTIC } & \multirow[b]{2}{*}{$N$} & \multicolumn{2}{|c|}{ PHYSICAL ABUSE } & \multicolumn{2}{|c|}{ SEXUAL ABUSE } & \multicolumn{2}{|c|}{ PSYCHOLOGICAL ABUSE } \\
\hline & & $\begin{array}{l}\text { CRUDE OR } \\
(95 \% \text { CI })\end{array}$ & $\begin{array}{l}\text { ADJUSTED OR } \\
(95 \% \mathrm{CI})\end{array}$ & $\begin{array}{l}\text { CRUDE OR } \\
(95 \% \mathrm{CI})\end{array}$ & $\begin{array}{l}\text { ADJUSTED OR } \\
(95 \% \mathrm{CI})\end{array}$ & $\begin{array}{l}\text { CRUDE OR } \\
(95 \% \mathrm{CI})\end{array}$ & $\begin{array}{l}\text { ADJUSTED OR } \\
(95 \% \mathrm{CI})\end{array}$ \\
\hline \multicolumn{8}{|l|}{ Gender } \\
\hline Female & 397 & $\begin{array}{l}0.370 \\
(0.136,1.006)\end{array}$ & $\begin{array}{l}0.352 \\
(0.120,1.032)\end{array}$ & $\begin{array}{l}0.517 \\
(0.136,1.961)\end{array}$ & $\begin{array}{l}0.466 \\
(0.111,1.964)\end{array}$ & $\begin{array}{l}0.833 \\
(0.633,1.097)\end{array}$ & $\begin{array}{l}0.797 \\
(0.590,1.076)\end{array}$ \\
\hline Male & 540 & 1.000 & 1.000 & 1.000 & 1.000 & 1.000 & 1.000 \\
\hline Age & 937 & $\begin{array}{l}0.864^{* *} \\
(0.788,0.947)\end{array}$ & $\begin{array}{l}0.848^{* *} \\
(0.763,0.943)\end{array}$ & $\begin{array}{l}0.905 \\
(0.807,1.016)\end{array}$ & $\begin{array}{l}0.877 \\
(0.765,1.005)\end{array}$ & $\begin{array}{l}0.969^{* *} \\
(0.949,0.990)\end{array}$ & $\begin{array}{l}0.970^{*} \\
(0.947,0.993)\end{array}$ \\
\hline \multicolumn{8}{|l|}{ Education } \\
\hline Form 3 or below & 792 & $\begin{array}{l}1.285 \\
(0.168,9.831)\end{array}$ & $\begin{array}{l}2.100 \\
(0.242,18.256)\end{array}$ & - & - & $\begin{array}{l}1.585 \\
(0.863,2.909)\end{array}$ & $\begin{array}{l}1.825 \\
(0.960,3.472)\end{array}$ \\
\hline Form $4-7$ & 85 & $\begin{array}{l}3.654 \\
(0.416,32.131)\end{array}$ & $\begin{array}{l}3.753 \\
(0.368,38.261)\end{array}$ & - & - & $\begin{array}{l}2.042 \\
(0.981,4.250)\end{array}$ & $\begin{array}{l}2.344^{*} \\
(1.081,5.080)\end{array}$ \\
\hline Tertiary or above & 60 & 1.000 & 1.000 & 1.000 & 1.000 & 1.000 & 1.000 \\
\hline \multicolumn{8}{|l|}{ Disability } \\
\hline Yes & 33 & - & - & - & - & $\begin{array}{l}0.974 \\
(0.461,2.058)\end{array}$ & $\begin{array}{l}0.799 \\
(0.348,1.831)\end{array}$ \\
\hline No & 904 & 1.000 & 1.000 & 1.000 & 1.000 & 1.000 & 1.000 \\
\hline \multicolumn{8}{|l|}{ Chronic illness } \\
\hline Yes & 416 & $\begin{array}{l}1.623 \\
(0.704,3.741)\end{array}$ & $\begin{array}{l}2.473 \\
(0.962,6.359)\end{array}$ & $\begin{array}{l}0.462 \\
(0.122,1.753)\end{array}$ & $\begin{array}{l}0.839 \\
(0.200,3.509)\end{array}$ & $\begin{array}{l}1.015 \\
(0.773,1.333)\end{array}$ & $\begin{array}{l}1.093 \\
(0.814,1.467)\end{array}$ \\
\hline No & 521 & 1.000 & 1.000 & 1.000 & 1.000 & 1.000 & 1.000 \\
\hline \multicolumn{8}{|c|}{ Co-residence with Children } \\
\hline Yes & 592 & $\begin{array}{l}3.955^{*} \\
(1.166,13.410)\end{array}$ & $\begin{array}{l}2.991 \\
(0.805,11.118)\end{array}$ & $\begin{array}{l}1.535 \\
(0.404,5.825)\end{array}$ & $\begin{array}{l}0.891 \\
(0.208,3.811)\end{array}$ & $\begin{array}{l}1.016 \\
(0.767,1.346)\end{array}$ & $\begin{array}{l}0.876 \\
(0.644,1.193)\end{array}$ \\
\hline No & 345 & 1.000 & 1.000 & 1.000 & 1.000 & 1.000 & 1.000 \\
\hline \multicolumn{8}{|l|}{ New immigrant } \\
\hline Yes & 362 & $\begin{array}{l}0.687 \\
(0.280,1.686)\end{array}$ & $\begin{array}{l}0.481 \\
(0.161,1.434)\end{array}$ & $\begin{array}{l}1.328 \\
(0.402,4.385)\end{array}$ & $\begin{array}{l}0.917 \\
(0.239,3.510)\end{array}$ & $\begin{array}{l}0.947 \\
(0.717,1.251)\end{array}$ & $\begin{array}{l}0.902 \\
(0.674,1.209)\end{array}$ \\
\hline No & 575 & 1.000 & 1.000 & 1.000 & 1.000 & 1.000 & 1.000 \\
\hline
\end{tabular}




\begin{tabular}{|c|c|c|c|c|c|c|c|}
\hline \multicolumn{8}{|l|}{ Employed } \\
\hline \multirow[t]{2}{*}{ Yes } & 106 & 0.719 & $0.105^{*}$ & 0.761 & 0.087 & 1.417 & 1.038 \\
\hline & & $(0.166,3.110)$ & $(0.015,0.724)$ & $(0.096,6.007)$ & $(0.006,1.277)$ & $(0.940,2.136)$ & $(0.566,1.903)$ \\
\hline \multirow{2}{*}{\multicolumn{2}{|c|}{$\begin{array}{l}\text { No } \\
\text { Receiving social security }\end{array}$}} & 1.000 & 1.000 & 1.000 & 1.000 & 1.000 & 1.000 \\
\hline & & & & & & & \\
\hline \multirow[t]{2}{*}{ Yes } & 109 & - & - & 0.716 & 0.716 & 0.984 & 1.052 \\
\hline & & & & $(0.090,5.708)$ & $(0.077,6.692)$ & $(0.653,1.484)$ & $(0.678,1.633)$ \\
\hline No & 828 & 1.000 & 1.000 & 1.000 & 1.000 & 1.000 & 1.000 \\
\hline \multicolumn{8}{|l|}{ Indebtedness } \\
\hline \multirow[t]{2}{*}{ Yes } & 23 & - & - & - & - & 0.928 & 0.487 \\
\hline & & & & & & $(0.389,2.214)$ & $(0.170,1.398)$ \\
\hline No & 914 & 1.000 & 1.000 & 1.000 & 1.000 & 1.000 & 1.000 \\
\hline \multicolumn{8}{|l|}{ Income } \\
\hline \multirow[t]{2}{*}{ No income } & 729 & 0.373 & $0.189^{*}$ & 0.357 & $0.129^{*}$ & $0.639^{*}$ & 0.731 \\
\hline & & $(0.131,1.059)$ & $(0.036,0.987)$ & $(0.093,1.369)$ & $(0.019,0.880)$ & $(0.417,0.978)$ & $(0.397,1.346)$ \\
\hline \multirow[t]{2}{*}{ HK $\$ 4,999$ or below } & 104 & 0.775 & 0.661 & - & - & 0.598 & 0.612 \\
\hline & & $(0.202,2.976)$ & $(0.097,4.482)$ & & & $(0.337,1.060)$ & $(0.311,1.202)$ \\
\hline HK $\$ 5,000$ or above & 102 & 1.000 & 1.000 & 1.000 & 1.000 & 1.000 & 1.000 \\
\hline
\end{tabular}

$\mathrm{OR}=$ odds ratio; Adjusted $\mathrm{OR}=$ odds ratio controlling for all variables: $\mathrm{CI}=$ confidence interval

${ }^{*} \mathrm{p}<0.05$; $^{* *} \mathrm{p}<0.01$; $^{* * *} \mathrm{p}<0.001$ 
Table 4. Psychological and behavioral correlates associated with preceding-year IPV victimization as shown by regression analyses

\begin{tabular}{|c|c|c|c|c|c|c|c|}
\hline \multirow[b]{2}{*}{ CHARACTERISTIC } & \multirow[b]{2}{*}{$N$} & \multicolumn{2}{|c|}{ PHYSICAL ABUSE } & \multicolumn{2}{|c|}{ SEXUAL ABUSE } & \multicolumn{2}{|c|}{ PSYCHOLOGICAL ABUSE } \\
\hline & & $\begin{array}{l}\text { CRUDE OR } \\
(95 \% \mathrm{CI})\end{array}$ & $\begin{array}{l}\text { ADJUSTED OR } \\
(95 \% \mathrm{CI})\end{array}$ & $\begin{array}{l}\text { CRUDE OR } \\
(95 \% \mathrm{CI})\end{array}$ & $\begin{array}{l}\text { ADJUSTED OR } \\
(95 \% \mathrm{CI})\end{array}$ & $\begin{array}{l}\text { CRUDE OR } \\
(95 \% \mathrm{CI})\end{array}$ & $\begin{array}{l}\text { ADJUSTED OR } \\
(95 \% \mathrm{CI})\end{array}$ \\
\hline \multicolumn{8}{|c|}{ Conflict with children in-law (Preceding-year) } \\
\hline Yes & 25 & $\begin{array}{l}2.322 \\
(0.288,18.723)\end{array}$ & $\begin{array}{l}0.394 \\
(0.026,5.903)\end{array}$ & - & - & $\begin{array}{l}2.240 \\
(0.972,5.164)\end{array}$ & $\begin{array}{l}2.199 \\
(0.861,5.616)\end{array}$ \\
\hline No & 624 & 1.000 & 1.000 & 1.000 & 1.000 & 1.000 & 1.000 \\
\hline \multicolumn{8}{|l|}{ Substance abuse } \\
\hline Yes & 58 & $\begin{array}{l}7.189^{* * *} \\
(2.830,18.258)\end{array}$ & $\begin{array}{l}20.763^{* * *} \\
(5.005,86.127)\end{array}$ & $\begin{array}{l}13.113^{* * *} \\
(3.876,44.366)\end{array}$ & $\begin{array}{l}35.330^{* * *} \\
(5.550,224.886)\end{array}$ & $\begin{array}{l}1.157 \\
(0.665,2.014)\end{array}$ & $\begin{array}{l}0.815 \\
(0.389,1.707)\end{array}$ \\
\hline No & 854 & 1.000 & 1.000 & 1.000 & 1.000 & 1.000 & 1.000 \\
\hline \multicolumn{8}{|c|}{ Childhood witnessed parental violence } \\
\hline Yes & 18 & $\begin{array}{l}2.326 \\
(0.296,18.264)\end{array}$ & - & $\begin{array}{l}5.431 \\
(0.656,44.990)\end{array}$ & - & $\begin{array}{l}5.982^{* *} \\
(1.934,18.502)\end{array}$ & $\begin{array}{l}5.215^{*} \\
(1.283,21.203)\end{array}$ \\
\hline No & 892 & 1.000 & 1.000 & 1.000 & 1.000 & 1.000 & 1.000 \\
\hline \multicolumn{8}{|l|}{ Criminal history } \\
\hline Yes & 18 & $\begin{array}{l}5.196^{*} \\
(1.123,24.055)\end{array}$ & $\begin{array}{l}18.281^{* *} \\
(2.750,121.510)\end{array}$ & $\begin{array}{l}5.118 \\
(0.620,42.250)\end{array}$ & $\begin{array}{l}21.108^{*} \\
(1.508,295.538)\end{array}$ & $\begin{array}{l}1.794 \\
(0.705,4.564)\end{array}$ & $\begin{array}{l}1.501 \\
(0.462,4.875)\end{array}$ \\
\hline No & 894 & 1.000 & 1.000 & 1.000 & 1.000 & 1.000 & 1.000 \\
\hline Domination & 937 & $\begin{array}{l}0.868 \\
(0.438,1.721)\end{array}$ & $\begin{array}{l}0.722 \\
(0.126,4.140)\end{array}$ & $\begin{array}{l}0.633 \\
(0.183,2.192)\end{array}$ & $\begin{array}{l}0.216 \\
(0.021,2.203)\end{array}$ & $\begin{array}{l}0.738^{* *} \\
(0.590,0.923)\end{array}$ & $\begin{array}{l}0.743 \\
(0.508,1.086)\end{array}$ \\
\hline Jealousy & 937 & $\begin{array}{l}1.071 \\
(0.664,1.727)\end{array}$ & $\begin{array}{l}0.640 \\
(0.185,2.212)\end{array}$ & $\begin{array}{l}1.059 \\
(0.529,2.118)\end{array}$ & $\begin{array}{l}0.845 \\
(0.187,3.806)\end{array}$ & $\begin{array}{l}0.871 \\
(0.736,1.030)\end{array}$ & $\begin{array}{l}0.818 \\
(0.626,1.069)\end{array}$ \\
\hline Anger management & 937 & $\begin{array}{l}0.727 \\
(0.247,2.141)\end{array}$ & $\begin{array}{l}0.808 \\
(0.093,7.017)\end{array}$ & $\begin{array}{l}0.404 \\
(0.065,2.498)\end{array}$ & $\begin{array}{l}0.308 \\
(0.015,6.376)\end{array}$ & $\begin{array}{l}0.441^{* * *} \\
(0.302,0.645)\end{array}$ & $\begin{array}{l}0.393^{* *} \\
(0.229,0.675)\end{array}$ \\
\hline Social support & 937 & $\begin{array}{l}0.211^{* *} \\
(0.075,0.588)\end{array}$ & $\begin{array}{l}0.149^{*} \\
(0.029,0.761)\end{array}$ & $\begin{array}{l}0.232 \\
(0.054,1.004)\end{array}$ & $\begin{array}{l}0.298 \\
(0.036,2.458)\end{array}$ & $\begin{array}{l}0.808 \\
(0.606,1.078)\end{array}$ & $\begin{array}{l}1.169 \\
(0.774,1.767)\end{array}$ \\
\hline Stressful conditions & 937 & $\begin{array}{l}0.518 \\
(0.243,1.104)\end{array}$ & $\begin{array}{l}0.386 \\
(0.100,1.499)\end{array}$ & $\begin{array}{l}0.546 \\
(0.186,1.604)\end{array}$ & $\begin{array}{l}0.403 \\
(0.073,2.233)\end{array}$ & $\begin{array}{l}1.136 \\
(0.919,1.404)\end{array}$ & $\begin{array}{l}1.397^{*} \\
(1.015,1.924)\end{array}$ \\
\hline
\end{tabular}

$\mathrm{OR}=$ odds ratio; Adjusted $\mathrm{OR}=$ odds ratio controlling for all variables: $\mathrm{CI}=$ confidence interval.

${ }^{*} \mathrm{p}<0.05 ;{ }^{* *} \mathrm{p}<0.01 ;{ }^{* * *} \mathrm{p}<0.001$. 
respondents with substance abuse and/or a criminal history were in fact more likely to become victims of IPV. It is possible that older IPV victims in the present study may have used drugs and/or alcohol as a means to "self-medicate." Exposure to repeated interpersonal traumatic events has been associated with alcohol use (Nelson et al., 2002). Female IPV victims, in particular, reportedly use alcohol to cope with the trauma arising from domestic violence (Kaysen et al., 2007). IPV in older couples is thus intertwined in a network of social issues and problems, and any effort to understand domestic violence must take a variety of factors into consideration.

This study also found that witnessing parental violence in childhood was associated with the present experience of psychological abuse. This is consistent with the hypothesis of a pattern of intergenerational transmission of violence and revictimization. Indeed, a reported meta-analysis showed previous experience of witnessing/ experiencing family-of-origin violence to be a risk factor for subsequent victimization (Riggs et al., 2000).

Consistent with previous IPV studies in the Chinese population (e.g. Chan, 2004; Xu et al., 2005), we found domination and anger management to be associated with psychological abuse in older couples. While previous studies examined perpetrators' high level of domination and low levels of anger management predictive of domestic violence (e.g. Vives-Cases et al., 2009), our study shows the lack of assertiveness and anger management on the part of the victim to be predictive of a high level of psychological aggression on the part of the perpetrator.

We also found a low level of social support to be predictive of physical assault. This is consistent with the elder abuse literature, which shows social isolation and a lack of social support to be important factors contributing to a mistreatment by caregivers (Lachs et al., 1994; Compton et al., 1997). Having limited social support, older IPV victims may find themselves dependent on the abuser, making it difficult or essentially impossible for them to leave the abusive relationship. Previous studies on elder abuse also found that victims perceive themselves as being emotionally dependent on their relationship with the abuser (Yan and Tang, 2004).

Several limitations of the present study warrant consideration. Since this study was based on crosssectional data, no conclusion about the causal relationship between the risk factors and IPV can be drawn. For the same methodological reason, the changes in IPV perpetration and victimization could not be captured over time. The data relied on the respondent self-reports and no external validation of these reports could be conducted in this study. Furthermore, although the present analysis is based on a subset of a representative population sample, the sample does not adequately reflect the demographics of the older population in Hong Kong. While previous studies showed that older persons with dementia were at elevated risks of family violence, no attempt has been made to identify the participants with dementia or cognitive impairment in this study. These are important factors which need to be examined in future studies.

However, despite these limitations, this study did employ both a representative sample and validated measures. The results suggest that IPV among older Chinese couples resembles both elder abuse and IPV as reported in the literature. However, given the complexity of the phenomenon, further studies should be conducted to investigate this preliminary finding and to better understand the driving mechanisms of IPV in older couples. IPV in older couples is a highly complicated phenomenon that is heavily intertwined with other forms of domestic violence and abuse, including spousal violence, child abuse, in-law conflicts, and elder abuse. Until we have a more definitive analysis and clear evidence as to whether IPV in older couples should come under the category of spousal abuse or elder abuse, it is advisable to treat it as a separate category of family violence related to both.

\section{Conflict of interest}

None.

\section{Description of the authors' roles}

E. Yan formulated the research questions and wrote the paper. E. Chan formulated the research questions, designed the study, and supervised data collection and analysis.

\section{Acknowledgments}

This study was commissioned by the Social Welfare Department and the Government of Hong Kong and funded by the Lotteries Fund.

\section{References}

Anetzberger, G. J., Korbin, J. E. and Austin, C. (1994). Alcoholism and elder abuse. Fournal of Interpersonal Violence, 9, 184-193.

Barnett, O. W., Miller-Perrin, C. L. and Perrin, R. D. (1997). Family Violence Across the Lifespan: An Introduction. Thousand Oaks, CA: Sage.

Chan, K. L. (2004). Correlates of wife assault in Hong Kong Chinese families. Violence and Victims, 19, 189-201. 
Chan, K. L., Brownridge, D. A., Tiwari, A., Fong, D. and Leung, W. C. (2008). Understanding violence against Chinese women in Hong Kong: an analysis of risk factors with a special emphasis on in-law conflict. Violence Against Women, 14, 1295-1312.

Choi, N. G. and Mayer, J. (2000). Elder abuse, neglect, and exploitation: risk factors and prevention strategies. Fournal of Gerontological Social Work, 33, 5-23.

Compton, S. A., Flanagan, P. and Gregg, W. (1997). Elder abuse in people with dementia in Northern Ireland: prevalence and predictors in cases referred to a psychiatry of old age service. International fournal of Geriatric Psychiatry, 12, 632-635.

Dutton, D. G. and Nicholls, T. L. (2005). The gender paradigm in domestic violence research and theory: Part 1the conflict of theory and data. Aggression and Violent Behavior, 10, 680-714.

Eckley, S. and Vilakazi, P. (1995). Elder abuse in South Africa. In J. Kosberg and J. Garcia (eds.), Elder Abuse: International and Cross Cultural Perspective (pp. 171-182). New York: Harworth Press.

Jasinski, J. L. and Dietz, T. L. (2003). Domestic violence and stalking among older adults: an assessment of risk markers. Fournal of Elder Abuse E Neglect, 15, 3-18.

Kantor, K. G. and Straus, M. A. (1999). Report on the USAF Family Needs Screener. Durham, NH: Family Research Laboratory, University of New Hampshire.

Kaysen, D. et al. (2007). Domestic violence and alcohol use: trauma-related symptoms and motives for drinking. Addictive Behaviors, 32, 1272-1283.

Lachs, M. S., Berkman, L., Fulmer, T. and Horwitz, R. (1994). A prospective community-based pilot study of risk factors for the investigation of elder mistreatment. Fournal of the American Geriatrics Society, 42, 169-173.

Leung, W. C., Leung, T. W., Lam, Y. Y. and Ho, P. C. (1999). The prevalence of domestic violence against pregnant women in a Chinese community. International Fournal of Gynaecology and Obstetrics, 66, 23-30.

Lundy, M. and Grossman, S. F. (2004). Elder abuse: spouse/intimate partner abuse and family violence among elders. Fournal of Elder Abuse $\mathcal{E}$ Neglect, 16, 85-102.

National Center on Elder Abuse (1998). The National Elder Abuse Incidence Study. New York.

Nelson, E. C. et al. (2002). Association between self-reported childhood sexual abuse and adverse psychosocial outcomes: results from a twin study. Archives of General Psychiatry, 59, 139-145.

Parish, W. L., Wang, T., Laumann, E. O., Pan, S. and Luo, Y. (2004). Intimate partner violence in China: national prevalence, risk factors and associated health problems. International Family Planning Perspectives, 30, 174-181.

Pillemer, K. and Finkelhor, D. (1988). The prevalence of elder abuse: a random sample survey. Gerontologist, 28, 51-57.

Riggs, D. S., Caulfield, M. B. and Street, A. B. (2000). Risk for domestic violence: factors associated with perpetration and victimization. Fournal of Clinical Psychology, 56, 1289-1316.

Shugarman, L. R., Fries, B. E., Wolf, R. S. and Morris, J. N. (2003). Identifying older people at risk of abuse during routine screening practices. Fournal of the American Geriatrics Society, 51, 24-31.

Straka, S. and Montminy, L. (2006). Responding to the needs of older women experiencing domestic violence. Violence Against Women, 12, 251-267.

Straus, M. A. (1990). The Conflict Tactics Scales and its critics: an evaluation and new data on validity and reliability. In M. A. Straus and R. J. Gelles (eds.), Physical Violence in American Families: Risk Factors and Adaptations to Violence in 8,145 Families (pp. 49-74). New Brunswick, NJ: Transaction Publishers.

Straus, M. A. (2004). Cross-cultural reliability and validity of the Revised Conflict Tactics Scales: a study of university student dating couples in 17 nations. Cross-Cultural Research, 38, 407-432.

Straus, M. A. and Mouradian, V. E. (1999). Preliminary Psychometric Data for the Personal and Relationships Profile (PRP): A Multi-Scale Tool for Clinical Screening and Research on Partner Violence. Paper presented at the American Society of Criminology. Toronto, Ontario, Canada.

Straus, M. A., Hamby, S. L., Boney-McCoy, S. and Sugarman, D. B. (1996). The revised Conflict Tactics Scales (CTS2): development and preliminary psychometric data. Fournal of Family Issues, 17, 283-316.

Vives-Cases, C., Gil-González, D. and Carrasco-Portiño, M. (2009). Verbal marital conflict and male domination in the family as risk factors of intimate partner violence. Trauma, Violence and Abuse, 10, 171-180.

Wilke, D. and Vinton, L. (2005). The nature and impact of domestic violence across age cohorts. Affilia, 20, 316-328.

Xu, X. et al. (2005). Prevalence of and risk factors for intimate partner violence in China. American fournal of Public Health, 95, 78-85.

Yan, E. and Tang, C. (2004). Elder abuse by caregivers: a study of prevalence and risk factors in Hong Kong Chinese Families. Fournal of Family Violence, 19, 269-277. 